\title{
Title-Botulinum Toxin and Gummy Smile- A Review
}

\author{
Dr. Dolly Patel ${ }^{1}$, Dr.Falguni Mehta ${ }^{2}$, Dr. Rahul Trivedi ${ }^{3}$, \\ Dr. Sandip Thakkar ${ }^{4}$, Dr. Jaymin Suthar ${ }^{4}$ \\ 1-Professor and head, Dept.of orthodontics, Govt.dental College and hospital, Ahmedabad, Gujarat, India \\ 2-Assistant Professor, Dept.of orthodontics, Govt.dental College and hospital, Ahmedabad, Gujarat, India \\ 3-Tutor, Dept.of orthodontics, Govt.dental College and hospital, Ahmedabad, Gujarat, India \\ 4-PG part-III., Dept.of orthodontics, Govt.dental College and hospital, Ahmedabad, Gujarat, India
}

\begin{abstract}
A smile is one of the most effective means by which people convey their emotions. When an excess of gingiva superior to the maxillary anterior teeth is displayed upon full smile, it is termed a gingival smile or Gummy smile. Treatment modalities for gummy smile change according to its etiology. One cause of excessive gingival display is the muscular capacity to raise the upper lip higher than average. Several surgical procedures have been reported to improve the condition, but surgery always involves risk and is costly. Botulinum toxin type A (BTX-A) (Botox; Allergan, Irvine, Calif) has been studied since the late 1970s for the treatment of several conditions associated with excessive muscle contraction. Injection with BTX-A at preselected sites is a novel, cosmetically effective, minimally invasive alternative for the temporary improvement of gummy smiles caused by hyperfunctional upper lip elevator muscles.
\end{abstract}

Key Words: NEUROMUSCULAR CORRECTION, GUMMY SMILE, BOTOX

\section{Introduction}

Recognizably cosmetic dental treatment dates back more than four millennia. According to Hulsey, "A smile is one of the most effective means by which people convey their emotions." The smile, along with speech, is what most visibly displays the results of orthodontic treatment; therefore, smile esthetics becomes a major goal in orthodontic treatment. Often, the main reason people seek orthodontic treatment is to improve dental esthetics. ${ }^{1}$

Patients and parents on orthodontic treatment demands and appreciates more of aesthetic harmony, so along with functionally efficient and balanced occlusion, good esthetics - dynamic smile has become one of the treatment goals of the orthodontist.

The best orthodontically treated subjects may not be satisfied by the treatment, if soft tissue problem is not corrected. Patient desire to look good not only in a static pose but also during dynamic facial expression.

Since the discovery of the cosmetic use of botulinum toxin, it has been rapidly incorporated into the arsenal of effective treatments for the improvement of unaesthetic facial conditions in the last two decades. In addition to being the first-choice treatment for wrinkles located on the upper third of the face, botulinum toxin is also widely used in the prevention and correction of changes caused by muscle contraction in the middle and lower thirds of the face and neck, including gummy smile.

\section{History}

Botulinum is derived from the Latin word botulus, meaning sausage, and botulism was originally called "sausage poisoning" because it occurred after ingestion of poorly prepared blood sausage. Justinus Kerner (1786-1862) was the first to describe the features of botulism. ${ }^{2}$ Clostridium botulinum was first identified in 1897, in Belgium, by Professor Emile van Ermengem. In the same year, an antiserum for botulism was made. ${ }^{3}$

Dr Alan Scott, an ophthalmologist from the Smith-Kettlewell Eye Research Foundation, performed the first clinical tests on humans in 1978. ${ }^{4}$ Dr Michael Kane, a plastic surgeon has been performing Botulinum toxin injections for excessive gingival show since 1992. ${ }^{5}$ Niamtu has been performing Botulinum toxin injections for excessive gingival show since 1999. In 2005 Mario Polo used botulinum toxin for the treatment of gummy smile. Injection with Botulinum toxin type A at preselected sites is a novel, cosmetically effective, minimally invasive alternative for the temporary improvement of gummy smiles caused by hyper functional upper lip elevator muscles. ${ }^{6}$

\section{Serotypes}

Food-borne botulism was the first form of the disease to be recognized. Botulinum toxin exists in seven different serotypes, designated A, B, C, D, E, F, and G. ${ }^{78}$ 


\section{Pharmacology Of Drug}

Botulinum toxin is synthesized by $C$. botulinum, C. butyricum, and $C$. baratii, all of which are anaerobic spore forming bacilli. ${ }^{9}{ }^{10}$ The spores are heat resistant, and they can germinate to produce toxin in the appropriate environment of anaerobic conditions, low acidity, and liquid medium, as found in some foods. The toxin is ingested and absorbed through the gastrointestinal tract into the systemic circulation. ${ }^{11}$

The action of Botulinum toxin at the neuromuscular junction is to interrupt transmission and in effect to denervate muscle. This chemodenervation effect persists for weeks to months. The duration of effect may depend on serotype. The mechanism for this extended duration has been hypothesized to arise from either continued protease activity within the cell or from persistent interference by cleaved substrate with normal membrane fusion. Currently, there is no known way to reverse the paralytic effects of Botulinum toxin after it has been internalized. Both active and passive immunization can inactivate toxin in the circulation, but antibody cannot enter nerves to neutralize internalized toxin. ${ }^{12-13}$

Recovery from Botulinum toxin occurs spontaneously and may take months to be complete. At the cellular level, 3 to 4 weeks after a single injection of Botulinum toxin/A in mice, there is sprouting of new processes along the nerve axon, with formation of multiple synapses with the muscle and up regulation of the muscle nicotinic receptors. Subsequently, the neuronal sprouts undergo regression and the original synaptic connection is restored, with restoration of the original neuromuscular junction. ${ }^{14}$

\section{Gummy Smile}

When an excess of gingiva superior to the maxillary anterior teeth is displayed upon full smile, it is termed a gingival smile. The gingival smile is known by a variety of terms including "gummy smile, high lip line, short upper lip, and full denture smile." Perhaps this variety in terms is indicative of the many different causes of a gummy smile. ${ }^{15}$

The smile itself and the aesthetics of the smile are influenced by 3 components: teeth, gums, and lips. An attractive smile depends on the proper proportion and arrangement of these 3 elements. The upper lip should symmetrically expose up to $3 \mathrm{~mm}$ of the gum and the gum line must follow the contour of the upper lip. The exposure of more than $3 \mathrm{~mm}$ of the gum during the smile is known as gingival or gummy smile. For some patients, gummy smile represents an aesthetic disorder. Hulsey noted that the most attractive smiles were those in which the upper lip rested at the height of the gingival margin of the maxillary incisor. ${ }^{16}$

Tjan et al reported gender differences in the smile line. In men, the authors report that the low smile line is predominant (2.5:1), whereas high smile lines are predominant in women $(2: 1){ }^{17}$

Gummy smiles range from mild, moderate, and advanced, to severe. Rosemarie Mazzuco et al., classified gummy smile into anterior, posterior, mixed, or asymmetric, based on the excessive contraction of muscles involved. Goldstein classified the smile line (consisting of the lower edge of the upper lip during the smile) according to the degree of exposure of the teeth and gums into 3 types: high, medium, or low. ${ }^{18}$

\section{Anatomy}

The shape of the mouth and the posture of the lips are controlled by a complex three-dimensional assembly of muscular slips. Gummy smile has always been regarded as the excessive exposure of the anterior gum, because most authors consider the LLSAN muscle to be mainly responsible for. However, all the muscles functionally involved in raising the upper lip have a role in tooth and gum display during smiling: LLSAN, levator labii superioris, ZM, zygomaticus minor, levator anguli oris (LAO), orbicularis oris, and risorius. A therapeutic approach in which the LLSAN muscle alone is treated with botulinum toxin may be insufficient when other muscles are involved in the excessive exposure, both anterior and posterior, of the gums. Moreover, in the case of posterior gummy smile, the zygomaticus muscles are more functionally involved than the other muscles of the upper lip lift complex, and the conventional application of botulinum toxin to relax the LLSAN muscle would cause unnecessary lowering of the lip in the medial region, an undesirable result from the aesthetic and functional standpoint. The three lip elevator muscles-LLS, LLSAN, and ZMi-converged on the area lateral to the ala. ${ }^{19}$

Causes Of A Gummy Smile ${ }^{15172122}$

○ Pre-Treatment

- Sex Predilection

- Musculature and Lip Incompetence

- Altered Passive Eruption

- Skeletal Disharmonies 
- Possible Causes of Gummy Smile Development During Orthodontic Treatment 222324

- Unexpressed Vertical Growth

- Extrusive Forces

- Anterior-Posterior Position of the Maxilla

TREATMENT FOR GUMMY SMILE

\begin{tabular}{|l|l|}
\hline Altered passive eruption:Type1a & Gingivectomy \\
\hline Altered passive eruption:Type1b & Crown lengthening \\
\hline Altered passive eruption:Type2 & $\begin{array}{l}\text { Apical reduction of the entire dentogingival complex with or } \\
\text { without osseous reduction }\end{array}$ \\
\hline Incorrect dental and skeletal relationship & $\begin{array}{l}\text { Orthodontic intrusion, orthognathic surgery, and orthodontic } \\
\text { implants }\end{array}$ \\
\hline Hyperfunctional lip elevator muscle & $\begin{array}{l}\text { Muscle resection, anterior nasal spine implant and botulinum } \\
\text { toxin }\end{array}$ \\
\hline
\end{tabular}

\section{Preparation, Storage, And Injection Technique}

Botox ${ }^{\circledR}$ is available in a freeze-dried powder that clumps at the bottom of the vial. During reconstitution, the rubber seal on the vial should be wiped with an alcohol swab before using a $5 \mathrm{ml}, 25$-guage needle syringe to inject the desired volume of normal preservative-free saline. Rotating the vial during injection also assists a gentle reconstitution. Botox ${ }^{\circledR}$ should be reconstituted after the journey. Agitation during transport may denature the toxin and greatly reduces its duration of action.

Almost all of the injections are intramuscular and not subcutaneous. One ml tuberculin or insulin syringes can be used as it gauges the dose accurately in minute quantities also. ${ }^{25-26} \mathrm{~A}$ safe and reproducible injection point for Botulinum toxin A around the converging area of the three muscles has been proposed and proved effective in clinical applications.

Intramuscular injection for correction of excessive gingival display is given at "Yonsei poing". (WooSang Hwang ).(fig-1) Botulinum toxin-A is diluted by adding $4.0 \mathrm{ml}$ of $0.9 \%$ normal saline solution without preservatives to $100 \mathrm{U}$ of vacuum-dried $C$ botulinum type A neurotoxin complex, according to the manufacturer's dilution technique. This results in a $2.5 \mathrm{U} / 0.1 \mathrm{ml}$ dose. ${ }^{27}$

\section{Asymmetric Smile}

In cases involving asymmetry caused by muscle contraction, bilateral injection of botulinum toxin is recommended, with a higher dose on the hyperkinetic side. This detail avoids reverse asymmetry with imbalance as a result of muscle contraction on the untreated side.An exception to this recommendation should be made when the asymmetry of the smile is a result of facial paralysis, in which case it is recommended that botulinum toxin is injected only into the hyperkinetic side. ${ }^{18}$

\section{Older Patients}

As a result of muscle weakness, skin flaccidity, and other alterations associated with aging, people older than 60 years may respond disproportionately to the usual doses of botulinum toxin. It is therefore recommended that all patients receive individualized doses, and in case of any doubt, lower doses to be used, with later retouching being performed if necessary.

Esthetic Botulinum toxin application in patients older than 75 years of age has not been adequately studied. In general, those older than 75 years of age are initially treated more conservatively. This is done as a cautionary move to offset the greater frequency of undiagnosed neurologic and medical disorders, higher likelihood of other drug therapy interactions, and higher susceptibility of older patients to functional problems. 18 


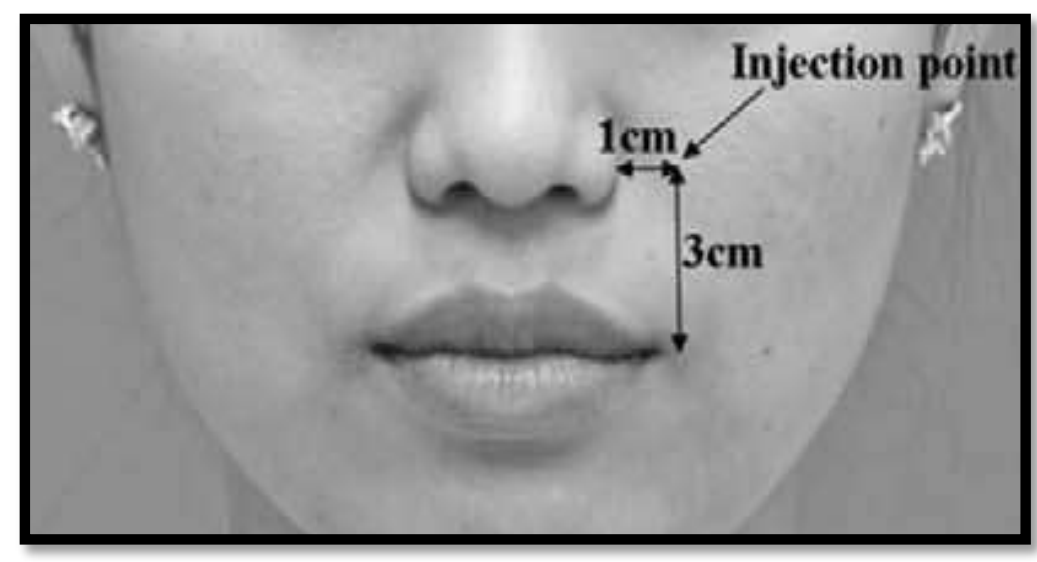

(Fig.1- Location of 'Yonsei point")

\section{Repeated Uses}

In a significant number of patients, reduced gum exposure after several applications of botulinum toxin has been noticed even after the effect of the drug has declined. This fact can be explained by the decrease in muscle strength that is likely to occur after several consecutive applications of botulinum toxin for any particular indication making it last for a longer period of time. It is important that the physician identify such cases, in subsequent applications, and reduce the dose to avoid an exaggerated effect. ${ }^{18}$

\section{Drug Interaction}

Drugs that may alter the effects of Botulinum toxin include: aminoglycosides (gentamycin), cyclosporine, D-penicillamine, muscle relaxants (cu-rare-type nondepolarizing blockers, succinylcholine), aminoquinolones, quinidine, magnesium sulfate, and lincosamide ${ }^{28}$

\section{Contraindication ${ }^{26}$}

Patients should not be treated or treated with extreme caution who are:

- Psychologically unstable or who have questionable motives and unrealistic expectations.

- Dependent on intact facial movements and expressions for their livelihood (e.g. actors, singers, musicians and other media personalities).

- Afflicted with a neuromuscular disorder (e.g. myasthenia gravis, Eaton-Lambert syndrome).

- Allergic to any of the components of BTX-A or BTX-B (i.e. BTX, human albumin, saline, lactose and sodium succinate).

- Taking certain medications that can interfere with neuromuscular impulse transmission and potentiate the effects of BTX (e.g. aminoglycosides, penicillamine, quinine, and calcium blockers).

- Pregnant or lactating (BTXs are classified as pregnancy category C drugs).

\section{ADVERSE EFFECTS ${ }^{29}$}

I. Adverse effects of limited duration that are common, localized and not of a serious nature:

Common with any percutaneous injection

- Mild stinging, burning or pain with injection

- Edema around injection site

- Erythema around injection site

- Mild headache, localized and transient

Technique dependent

- Ecchymosis lasting 3 to 10 days

- Asymmetry

- Oral incompetence and asymmetric smile

- Lack of intended cosmetic effect

Rare and idiosyncratic

- Numbness and paresthesias( localized and transient)

- Focal tonic movements (twitching)

- Mild nausea and occasional vomiting

- Mild malaise and myalgias (localized and generalized) 
II. Rare adverse effects of longer duration that can be serious and are not technique dependent :

- Immediate hypersensitivity reactions

- Urticaria

- Dyspnea

- Soft tissue edema

- Anaphylaxis

\section{Conclusion}

Injection with Botox-A at preselected sites is a novel, cosmetically effective, minimally invasive alternative for temporary improvement of gummy smiles caused by hyperfunctional upper labial muscle activity.

\section{References}

[1] Hulsey CM. An esthetic evaluation of lip-teeth relationships present in the smile. Am J Orthod. Dentofacial Orthop.1970; 57 (2):132-144.

[2] Textbook of microbiology, seventh edition-2005,reprint, Ananthnarayan and paniker.

[3] E. van Ergmengem. 1897. Über einen neuen anaeroben Bacillus und seine Beziehungen Zum Botulismus. Zentralbl. Hyg. Infektionskr. 26:1-8.

[4] Frank J. Erbguth. From poison to remedy: the chequered history of botulinum toxin Journal of neural transmission (2008) 115: $559-565$

[5] Kane MA. The effect of botulinum toxin injections on the nasolabial fold. Plast Reconstr Surg 2003;112:66S-72S.

[6] Mario Polo, Botulinum toxin type A in the treatment of excessive gingival display, Am J Orthod Dentofacial Orthop, 2005; 127:214-8.

[7] Fenicia L, Franciosa G, Pourshaban M, Aureli P. Intestinal toxemia botulism in two young people, caused by Clostridium butyricum type E. Clin Infect Dis. 1999; 29:1381-7. DOI: 10.1086/313497.

[8] Harvey SM, Sturgeon J, Dassey DE. Botulism due to Clostridium baratii type F toxin. J Clin Microbiol. 2002;40:2260-2. DOI:10.1128/JCM.40.6.2260-2262.2002Centers for Disease Control and Prevention. Botulism in the UnitedStates, 1899-1996.

[9] Handbook for epidemiologists, clinicians and laboratory workers. Atlanta: The Centers; 1998.

[10] Dolman CE, Murakami L. Clostridium botulinum type F with recent observations on other types. J Infect Dis. 196 ;109:107-28. 4.

[11] Midura TF, Nygaard GS, Wood RM, Bodily HL. Clostridium botulinum type F: isolation from venison jerky. Appl Microbiol. $1972 ; 24: 165-7$

[12] Rossetto, O., Caccin, P., Rigoni, M., Tonello, F., Bortoletto, N., Stevens, R.C., Montecucco, C., 2001a. Active-site mutagenesis of tetanus neurotoxin implicates TYR-375 and GLU-271 in metalloproteolytic activity. Toxicon 39, 1151-1159.

[13] Kate Coleman moriarty: Botulinum Toxin in Facial Rejuvenation; first print, 2004

[14] Brin, M. F., Dressler, D. \& Aoki, R. Pharmacology of botulinum toxin therapy. In J. Jankovic, C. Comella \& M. F. Brin, eds., Dystonia: Etiology, Clinical Features, and Treatment. Philadelphia: Lippincott Williams \& Wilkins, pp. 93-112.

[15] Peck S, Peck L, Kataja M. The gingival smile line. Angle Orthod. 1992; 62(2):91-100.

[16] Mackley RJ. An Evaluation of smiles before and after orthodontic treatment. Angle Orthod. 1993; 63(3): $183-189$.

[17] Tjan AH, Miller GD, The JG. Some esthetic factors in a smile. J Prosthet Dent. 1984; 51(1):24-28.

[18] Mazzuco and Hexsel: Gummy smile and botulinum toxin: A new approach based on the gingival exposure area. J AM Acad Dermatol, vol 63, no 6, 1042-1051.

[19] Susan Standring: Gray's anatomy; The Anatomical Basis of Clinical Practice, Expert Consult; 40 th edition, sep-2008.

[20] MARC B. ACKERMAN, JAMES L. ACKERMAN: Smile Analysis and Design in the Digital Era; jco-2002, vol36, no 4, pg: 221-

[21] Matthews TG. The anatomy of a smile. J Prosthet Dent. 1978; 39(2):128-134.

[22] Garber DA, Salama MA. The aesthetic smile: diagnosis and treatment. Periodontol. 2000. 1996; 11: 18-28. Fields HW, Proffit WR, Nixon WL, Phillips C, Stanek E. Facial pattern differences in long-faced children and adults. Am J Orthod. 1984; 85(3):217-223.

[23] Isaacson JR, Isaacson RJ, Speidel TM, Worms FW. Extreme variation in vertical facial growth and associated variation in skele tal and dental relations. Angle Orthod. 1971;41(3):219-229.

[24] Schendel SA, Eisenfeld J, Bell WH, Epker BN,Mishelevich DJ. The long face syndrome: vertical maxillary excess. Am J Orthod. Dentofacial Orthop. 1976; 70(4):398-408.

[25] Woo-Sang Hwang: Surface Anatomy of the Lip Elevator Muscles for the Treatment of Gummy Smile Using Botulinum Toxin Angle Orthod.2009; 79:70-77.

[26] Kate Coleman moriarty: Botulinum Toxin in Facial Rejuvenation; revised; 2006

[27] Mario Polo,Botulinum toxin type A (Botox) for the neuromuscular correction of excessive gingival display on smiling (gummy smile)Am J Orthod Dentofacial Orthop 2008;133:195-203.

[28] Daniel Troung, Dirk Dressler, Mark Hallett: Manual of botulinum toxin therapy; first print 2009.

[29] Kromminga, A. \& Schellekens, H. (2005). Antibodies against erythropoietin and other protein-based therapeutics: an overview. Ann N Y Acad Sci, 1050, 257-65. Hunt, T. J. (2007). Botulinum Toxin Composition, US Patent application 2007/0025019. 